\title{
Editorial
}

\section{Interpreting the Environmental Protocol - a recipe for international confusion?}

Turning international agreement into national law has never been rapid or simple. Each country has 1 its own parliamentary procedures, its own legal system and its own cultural interpretation of what the words in the international agreement actually mean. Last but not least, the importance attached to implementing Treaty law is clearly different between countries, as the amazingly patchy implementation of existing Treaty Recommendations shows.

Perhaps the lack of enthusiasm for existing Treaty Recommendations has been because most are hortatory not mandatory - a much less exciting prospect for the lawyers. The Protocol is different though. It is mandatory and its implementation in most countries is not likely to be a trivial matter.

Obviously there are various ways to implement the Protocol's provisions but the most straight forward way would seem to be an enabling framework act to provide the basic law followed by the enactment of specific regulations to deal with the particular activities which need to be controlled - waste management, protected areas, environmental impact assessment etc. This means that the regulations are likely to differ significantly between countries as there is no facility for harmonizing them.

A normal method of legal control of activities is to allow them under permit or permission. Thus the granting of permits may well become a major feature of the administration of scientific activities in the Antarctic. The rules for these permits and the authority to grant them are likely to vary considerably between countries, especially in cases where existing national non-Antarctic environmental legislation is used to provide the standards or procedures that will be applied to Antarctic activities.

What does this mean for scientists? The present rate of legal progress suggests that, even in another five years, not all the necessary primary let alone secondary legislation will have been passed by all the Consultative Parties. Thus, in any multinational expedition some scientists will be required legally to conform to new and exacting standards of environmental care whereas others may be governed by much less rigorous provisions or even none at all. Might environmental impact assessments be handled in such cases through the country with the least rigorous legislation? What about permit arrangements for entry into and the use of protected areas? The management plans should require a report after each visit as a condition of issuing the permit. Will there be significant differences between countries in the acceptable grounds for issuing permits? In the case of collaboration by invitation, what should be the attitude of a 'host' nation to the conduct of a foreign colleague from a country with a less exacting implementation of the Protocol? Memoranda of Understanding may become all-important in this respect.

We face several yea $s$ of potential confusion whilst the lawyers provide the laws, and this may be followed by more years of actual confusion when we see how differently the mandatory provisions are implemented. With the tendency for ever larger multi-national scientific activities the science community needs to keep a close eye on developments both nationally and internationally.

D W H WALTON M R A THOMSON 